\title{
Does Anterior Controllable Antidisplacement and Fusion Technique Improve Quality of Life in Revision Treatment for Cervical Ossification of the Posterior Longitudinal Ligament? Three-Year Follow- Up Study
}

Hai-Dong Li ( $\nabla$ hd_lee2008@163.com )

The first people' hospital of Huzhou, Zhejiang Province

Ji-Kang Min

The first people' hospital of Huzhou, Zhejiang Province

\section{Research Article}

Keywords: Cervical myelopathy, Ossification of the posterior longitudinal ligament, Revision, Antidisplacement, Functional scores

Posted Date: April 21st, 2021

DOI: https://doi.org/10.21203/rs.3.rs-408735/v1

License: (c) (1) This work is licensed under a Creative Commons Attribution 4.0 International License. Read Full License 


\section{Abstract}

Background: The laminoplasty and laminectomy are two comparatively safe posterior procedures for the treatment of OPLL. The long-term outcomes of posterior surgery seem to be favorable, however it is also criticized for $\mathrm{C} 5$ nerve root palsy, progression OPLL and bad cervical lordosis. An additional revision surgery was required for those patients who had the poor clinical improvement after the initial posterior surgery.

Methods: This study was to identify the mid-term clinical results and the health-related quality of life (HRQoL) after anterior controllable antidisplacement and fusion (ACAF) technique for revision treatment of cervical ossification of the posterior longitudinal ligament (OPLL). All the patients were followed up for more than 3 years. The Japanese Orthopaedic Association (JOA) scales, Neck Disability Index (NDI) and Short-Form 36 (SF-36) were recorded to evaluate the health-related quality of life. And the neck and arm pain scale as an expression of visual analog scale (VAS) were also collected. Intraoperative parameters, clinical features, radiological investigations and the surgery-related complications were performed to analysis.

Results: There were 20 patients who underwent ACAF revision surgery between March 2017 and January 2019. Clinical improvements were observed in all outcomes; significant improvements on the NDI, VAS, SF-36, and JOA scores were maintained at 3 years $(P<0.05)$. All the patients showed a better cervical alignment, and the average cervical lordosis was $17 \pm 4.6^{\circ}$ after revision surgery. There was only one case of cerebrospinal fluid (CSF) leakage, no instance of C5 root platy, postoperative hematoma or esophageal injury occured. No instrumented failure or pseudarthrosis case was observed during the follow-up.

Conclusions: This study suggested that ACAF is an effective and safe procedure for the revision treatment of cervical OPLL. Such a surgical technique can offer the postoperative improvement on pain levels and health-related quality of life.

\section{Background}

Cervical ossification of the posterior longitudinal ligament (OPLL) is a pathologic process of lamellar bone deposition at the site of the posterior longitudinal ligament, which frequently related to cervical myelopathy [1]. In the Asian countries, the incidence of OPLL is similarly reported up to 3\% [2]. Asymptomatic patients without severe cord compression can be treated conservatively; however, surgical intervention treatment should be considered for patients with progressive neurological deterioration [3-4]. A variety of surgical approaches have been described utilizing anterior, posterior, and combined anteroposterior approaches, each with unique risks and benefits.

The laminoplasty and laminectomy are two comparatively safe posterior procedures with few complication for the treatment of OPLL [5-6]. They decompress the spinal cord indirectly depending on the backward shift of the cervical spinal cord. The long-term outcomes of posterior surgery seem to be favorable, however it is also criticized for C5 nerve root palsy, progression OPLL and bad cervical lordosis 
[7-8]. Owing to the poor cervical alignment, the operative instability and the progressive ossified lesion, the neurological function of the patient will be always deteriorate $[5,9]$. And a additional revision surgery was required for those patients who had the poor clinical improvement after the initial posterior surgery [10]. The revision surgery was challenging because it maybe was a combination of progressive kyphosis, segmental instability, multi-level progressive OPLL [11].

The anterior controllable antidisplacement and fusion (ACAF) technique was reported for the treatment of multi-levels OPLL with cervical myelopathy [12]. The goal of this novel technique was to achieving direct decompression by make the ossified lesion "controllable floated", the space of cervical spinal canal was much wider with their location unchanged. Our previous study have proved the preliminary feasibility of this novel anterior approach as the revision method for the OPLL [13]. Although health-related quality of life (HRQoL) for anterior cervical diskectomy and fusion (ACDF) and cervical disk arthroplasty (CDA) has been largely investigated [14-15], there is fewer studies evaluating the quality of life regarding the revision surgery for cervical OPLL. Accordingly, the purpose of our study was to evaluate current data from a single center regarding revision surgery with ACAF technique for cervical OPLL; we present 3-year followup clinical and radiographic data for patients with initially failed posterior surgery.

\section{Materials And Methods}

\section{Patient population}

We prospectively collected data from a consecutive series of patients underwent ACAF revision surgery due to the OPLL from March 2017 to January 2019. They all had the progressive neurological deterioration after the initial posterior surgery. Patients with severe osteoporosis (criteria of WHO), preexisted spinal deformity, cervical spine trauma, spinal infections, and chronic systemic illnesses were excluded in this study. This study had been approved by Ethics Committee of the authors' affiliated institutions, and all the patients signed informed consent.

\section{Data collection and outcome evaluation}

Data including patient demographic, intraoperative details (type of OPLL, surgery time, amount of blood loss, complications), postoperative functional scores, and surgery-related complications were collected. During the follow-up, clinical and radiographic data were collected on the last day of hospital stay, at 1months, 3 months, 6 months, and every year after the surgery. All the patients were included in the clinical and radiographic evaluations at the each follow-up time point. The Japanese Orthopaedic Association Scores (JOA), Visual Analogue Score (VAS), Neck Disability Index (NDI) and the Medical Outcomes Study SF-36 Form Health Survey were used to measure the neck pain, arm pain and the neurological function. Odom grading system (poor, fair, good, or excellent) was used to evaluate patient satisfaction with the surgery.

The cervical lordosis indicates the angle between 2 crossed perpendicular lines that are extended parallel to inferior endplates of C-2 and C-7 on the standing lateral radiograph of the cervical spine. Kyphosis was 
defined as $\mathrm{C} 2-7 \mathrm{cobb}<0^{\circ}$. The anterposterior, lateral and flexion-extension images were taken at before the surgery, 1 months, 6 months, 12 months after the surgery. Pseudarthrosis was defined as interspinous motion of $>1 \mathrm{~mm}$ on dynamic flexion-extension images [16].

\section{Surgical technique}

All surgical procedures were performed under general anesthesia with endotracheal intubation, with the patients placed in supine position. The somatosensory-evoked potentials (SSEPs) was used to detect the neurological damage during the operation. The exposure was obtained through a Smith-Robinson approach on the right side. Firstly, discectomies of involved levels were carried out. During the decompression of the cephalad and caudal intertebral space, remove the ossified posterior longitudinal ligament. Then, resection of the anterior vertebral bodies of the Vertebrae-OPLL -Complex (VOC) is performed by a high-speed burr; Thirdly, we install the cage with autogenous bone and the anterior static plate. Fourthly, The bilateral osteotomies of the vertebrae along the medial of Luschka joint were made. Finally the VOC was hoisted by gradually tightening with screws. The illustration of the surgical procedures is shown in the Figure 1. Autogenous bone pieces were graft into the bilateral troughs to obtain further fusion. A hard cervical brace is routinely used postoperatively for 3 months.

\section{Statistical analysis}

Statistical analysis was performed using SPSS 16.0. Preoperative and postoperative data such as JOA, VAS, NDI and SF-36 scores were compared using paired t test, while Manne-Whitney U-test for categorical data, and Spearman rank correlation coefficient to investigate relationships. The level of significance was set at $p<0.05$.

\section{Results}

\section{clinical and radiographic results}

There were 20 patients with cervical OPLL who underwent ACAF revision surgery in this study. The patient demographic data is shown in Table 1. The mean age was $62.1 \pm 8.0$ (52-78), and the mean interval between the primary and revision surgery was $78.0 \pm 48.2$ months (range 5-180months). The mean operative time in this group was $179.3 \pm 41.8 \mathrm{~min}$ (range $120-240 \mathrm{~min}$ ). The mean intraoperative blood loss was $432.5 \pm 198.3 \mathrm{ml}$ (range $225-850 \mathrm{ml}$ ). All the patients had a minimum of 3 years'follow-up. The imaging of the typical cases were shown in Figure 2-3.

As shown in the Table 2, the preoperative JOA score was $8.7 \pm 2.8$, and the postoperative JOA was $13.4 \pm 2.4(p<0.05)$; Also, The postoperative VAS arm and neck score was $3.9 \pm 1.4,3.4 \pm 1.4$ separately, which both decreased significantly $(p<0.05)$. The preoperative NDI score was $24.4 \pm 3.0$, and the postoperative NDI was $13.3 \pm 2.7(p<0.05)$. Similarly, the SF-36 physical and mental subscore presented a similar pattern to the other outcome measures, significantly improved at 6 months post surgery. Using Odom criteria, $90 \%$ of patients rated their level of satisfaction with the surgery as excellent or good. The 
postoperative cervical lordosis was $17.2 \pm 4.6^{\circ}$, which was much better than that of preoperative. No patient show neurological deterioration after revision surgery, and all the patients had osseous-fusion at 3-year of follow-up.

During the follow-up, The JOA score demonstrated significant improvement at 3 months after surgery (P $<0.05$ ), without significant variations during the later follow-up. The NDI demonstrated significant improvement at 3-year follow-up from a preoperative score $(P<0.05)$, with significant improvements seen by 6 months after surgery $(P<0.05)$ and maintained over time. The largest reduction has been observed at 1-month follow-up both in the VAS arm and VAS neck score $(P<0.05)$, which was slight return of pain over a longer period of observation. With regard to the SF-36, both the physical subscore and mental subscore significantly improving at 6 months post surgery $(P<0.05)$, and then maintained the same trend for the rest of the follow-up. Figure 4 shows the change in clinical outcomes over time.

\section{complication}

There was only one case of CSF leakage (5\%) happened in our study. In that case, there was severe adhesion between the dural mater and the ossified posterior longitudinal ligament. Fortunately, it was healed by sponge and elastic bandage. There were no occurrences of postoperative hematoma, hoarseness, $\mathrm{C} 5$ root platy or instrumented failure.

\section{Discussion}

In the present study, we have evaluated HRQoL in a group of revision patients suffering from the cervical OPLL with a prospective design. Our results suggested that HRQoL significantly improve 3 years after discharge $(P<0.05)$. Such findings were consistent with earlier lines of evidence $[13,17]$. The present study is the first study to investigate the HRQoL of cervical OPLL patients with satisfaction for up 3 years after revision surgery with ACAF technique. It is suggested that VAS, JOA, NDI and SF-36 scores were all significantly improved after ACAF surgery $(P<0.05)$. Great improvement can continued for at least 6 months after the operation. During the follow-up, the greatest reduction in both neck and arm pain was observed at one month, and the pain improvement were no longer significantly at three years, maintaining almost the same score as which in the one year after surgery.

Posterior cervical surgery such as laminoplasty or laminectomy is relatively safe and with low complication rate, they were suggested as the favourite choice for the initial treatment of OPLL [11]. However, owing to the neurological deterioration after posterior surgery, some patients need additional revision surgery [18-19]. The great loss of cervical lordosis and the extensive OPLL progression might be the two main reasons for failure of the operation [20-22]. For posterior procedures, the revision rate after cervical foraminotomy has been reported to range from $2.9 \%$ at 7 years to $5 \%$ at 31.7 months compared to laminoplasty with a revision rate ranging from $2.1 \%$ at 15 years to $13 \%$ at 42.3 months, and laminectomy and fusion which has a revision rate ranging from $2 \%$ to $27 \%$ at 41.3 months [23-25]. Shigematsu et al [26] considered that the reasons for recurrence of symptoms after laminoplasty fall into three categories: technique related, inadequate treatment, and disease progression. Papavero et al [27] 
also classified the indications for cervical revision surgery(CRS) into five categories: adjacent segment disease (ASD), infection (INF), implant failure-pseudarthrosis (IFP), non-infectious complication, and deformity.

When the patient had progressive cervical neurological deterioration after initial surgery, a revision surgery should be considered. Papavero et al [27] thought cervical revision surgery required painstaking planning and mastery of a variety of surgical techniques. The results were rewarding in half and satisfactory in a quarter of the patients. The complication rate was lower than expected. It is very difficult to do the decompression surgery with the same posterior procedure. Koerner et al [25] suggested that the approach to revision cervical spine surgery depends on the etiology. In cases of postoperative kyphosis, the operative strategy is to lengthen the anterior column and shorten the posterior column, which is usually performed with anterior-posterior procedures. In cases of ASD without deformity, the approach is dependent on the location of the neural compression. It was reported that multi-level ACCF carries an approximately $22 \%$ risk of surgical mortality and morbidity, including deep vein thrombosis, pneumonia and death [28]. Odate et al [11] suggest that the use of anterior decompression revision surgery for OPLL must be limited owing to the high probability of CSF leakage and the low rate in neurological improvement. In their study, the incidence of surgery-related complications was as high as $63 \%$, the main complication being intraoperative CSF leakage (42\%), the mean improvement rate of the JOA score was $18 \%$ only. To minimize the surgical risk of CSF leakage, hemorrhage and spinal cord injury, Yamaura et al [29] reported the floating method for treatment of cervical myelopathy owing to the OPLL. However, the anterior migration of the ossified ligament in the this method is not controlled by the surgeon, but depending on the pressure of the CSF. There was approximately $14 \%$ of the cases with neurological deterioration owing to residual ossified lesion or the postoperative progression of OPLL.

The ACAF technique can restore the spinal canal by isolating and actively antedisplacing the OPLL ventrally, it achieved direct decompression without interference with the spinal cord. Differently from the previous floating technique, we make the antedisplacement of the OPLL through the gradual hoisting force by the anterior plate and screws with immediate feedback. The direct decompression of the spinal cord and nerve roots was the anatomic basis for the clinical effect. However, as a novel technique, the improvement of quality of life and the long-term efficacy remain uncertain. We have previously demonstrated that ACAF is an effective, reliable, and safe procedure for the treatment of OPLL [13]. Wang et al [30] also confirmed that ACAF could improve neurological function significantly for revision treatment after posterior decompression surgery. The present study is the first study to investigate the HRQoL of cervical OPLL patients after revision surgery with ACAF technique. A major strength of this study is that we conducted a face-to-face interview for HRQoL measurements both before and after the treatment with a follow-up spanning 3 years. However, there are some limitations. Small sample size may bias our results; Also, as similar to previous studies, we only recruited participants from a single hospital and the results might not be generalized to other settings or populations, particularly those with distinct socioeconomic or clinical backgrounds. 


\section{Conclusions}

Our study demonstrate that excellent mid-term clinical outcome can be achieved with the ACAF technique for cervical revision surgery. Such a surgical method has been shown to provide postoperative improvement on pain levels and on health-related quality of life, thus showing it to be a safe alternative to traditional anterior surgical methods. The findings in our study still need to be further confirmed by more investigations with larger sample sizes in external populations.

\section{Declarations}

\section{Ethics approval and consent to participate}

This study had been approved by Ethics Committee of the authors' affiliated institutions, and the informed consent to participate in the study should be obtained from all the patients.

\section{Consent for publication}

All patients provided written informed consent to use their clinical data for publication purposes.

\section{Availability of data and material}

The datasets used and/or analyzed during the current study are availabe from the corresponding author on reasonable request.

\section{Competing interests}

The authors declare that they have no conflict of interest.

\section{Funding}

This study was sponsored by the Medical Health Science and Technology Project of Zhejiang Province (2021421708) and Project of Huzhou Science and Technology Bureau(2020GY08).

\section{Authors' contributions}

HDL had full access to all of the data in the study and take responsibility for the integrity of the data and the accuracy of the data analysis. JKM was highly involved in the planning and execution of this study. The author(s) read and approved the final manuscript.

\section{Acknowledgements}

Not applicable.

\section{References}


1. Matsunaga S, Sakou T. Ossification of the posterior longitudinal ligament of the cervical spine: etiology and natural history. Spine. 2012;37:E309-E314.

2. Boody BS, Lendner M, Vaccaro AR. Ossification of the posterior longitudinal ligament in the cervical spine: a review. Int Orthop. 2019;43:797-805.

3. Iwasaki M, Okuda S, Miyauchi A, Sakaura H, Mukai Y, Yonenobu K, et al. Surgical strategy for cervical myelopathy due to ossification of the posterior longitudinal ligament: Part I: clinical results and limitations of laminoplasty. Spine (Phila Pa 1976). 2007;32:647-653.

4. Iwasaki M, Okuda S, Miyauchi A, Sakaura H, Mukai Y, Yonenobu K, et al. Surgical strategy for cervical myelopathy due to ossification of the posterior longitudinal ligament. Part 2: advantages of anterior decompression and fusion over laminoplasty. Spine (Phila Pa 1976). 2007;32: 654-660.

5. Iwasaki M, Kawaguchi Y, Kimura T, Yonenobu K. Long-term results of expansive laminoplasty for ossification of the posterior longitudinal ligament of the cervical spine: more than 10 years follow up. J Neurosurg. 2002;96:180-189.

6. Lee SE, Chung CK, Jahnq TA, Kim HJ. Long-term outcome of laminectomy for cervical ossification of the posterior longitudinal ligament. J Neurosurg Spine.2013;18:465-471.

7. Chen Y, Chen D, Wang X, Guo Y, He Z. C5 palsy after laminectomy and posterior cervical fixation for ossification of posterior longitudinal ligament. J Spinal Disord Tech. 2007;20:533-535.

8. Lee CK, Shin DA, Yi S, Kim KN, Shin HC, Yoon DH, et al. Correlation between cervical spine sagittal alignment and clinical outcome after cervical laminoplasty for ossification of posterior longitudinal ligament. J Neurosurg Spine. 2016;24:100-107.

9. Hirabayashi M, Watanabe K, Wakano K, Suzuki N, Satomi K, Ishii Y. Expansive open-door laminoplasty for cervical spinal stenotic myelopathy. Spine (Phila Pa 1976). 1983;8:693-699.

10. Tokuhashi Y, Ajiro Y, Umezawa N. A patients with two resurgeries for delayed myelopathy due to progression of ossification of the posterior longitudinal ligaments after cervical laminoplasty. Spine (Phila Pa 1976). 2009;34:E101-E105.

11. Odate S, Shikata J, Soeda S, Yamamura S, Kawaguchi S. Surgical results and complications of anterior decompression and fusion as a revision surgery after initial posterior surgery for cervical myelopathy due to ossification of the posterior longitudinal ligament. J Neurosurg Spine. 2017;26: 466-473.

12. Sun J, Shi J, Xu X, Yang Y, Wang Y, Kong Q, et al. Anterior controllable antidisplacement and fuion surgery for the treatment of multilevel severe ossification of the posterior longitudinal ligament with myelopathy: preliminary clinical results of a novel technique. Eur Spine J. 2017;17: 5437-5444.

13. Li HD, Zhang QH, Xing ST, Min JK, Shi JG, Chen XS, et al. A novel revision surgery for treatment of cervical ossification of the posterior longitudinal ligament after initial posterior surgery: preliminary clinical investigation of anterior controllable antidisplacement and fusion. J Orthop Surg Res. 2018;13:215.

14. Schroeder GD, Boody BS, Kepler CK, Kurd MF, Silva S, Nicholson K, et al. Comparing health-related quality of life outcomes in patients undergoing either primary or revision anterior cervical disectomy 
and fusion. Spine (Phila Pa 1976). 2018;43:E752-757.

15. Gornet MF, Burkus JK, Shaffrey ME, Schranck F, Copay AG. Cervical disc arthroplaty: 10-year outcomes of the prestige LP cervical disc at a single level. J Neurosurg Spine. 2019;31:317-325.

16. Song KS, Piyaskullkaew C, Chuntarapas T, Buchowski JM, Kim HJ, Park MS. Dynamic radiographic criteria for detecting pseudarthrosis following anterior cervical arthrodesis. J Bone Joint Surg Am. 2014;96:557-563.

17. Miao J, Sun J, Shi J, Chen Y, Chen D. A novel anterior revision surgery for the treatment of cervical ossification of the posterior longitudinal ligament: case report and review of the literature. World Neurosurg. 2018;113:212-216.

18. Matsumoto M, Chiba K, Toyama Y. Surgical treatment of ossification of posterior longitudinal ligament and its outcomes: posterior surgery by laminoplasty. Spine (Phila Pa 1976). 2012;37: E303308.

19. Sakai K, Okawa A, Takahashi M, Arai Y, Kawabata S, Enomoto M, et al. Five-year follow-up evaluation of surgical treatment for cervical myelopathy causd by ossification of posterior longitudinal ligament: a prospective comparative study of anterior decompression and fusion with floating method versus laminoplasty. Spine (Phila Pa 1976). 2012;37:367-376.

20. Lee $\mathrm{CH}$, Jahng TA, Hyun SJ, Kim KJ, Kim HJ. Expansive laminoplasty versus laminectomy alone versus laminctomy and fusion for cervical ossification of the posterior longitudinal ligament: is there a difference in the clinical outcome and sagittal alignment? Clin Spine Surg. 2016;29:E9-E15.

21. Liu H, Li Y, Chen Y, Wu W, Zou D. Cervical curvature, spinal cord MRIT2 signal, and occupying ratio impact surgical approach selection in patients with ossification of the posterior longitudinal ligament. Eur Spine J. 2013;22:1480-1488.

22. Lee $\mathrm{CH}$, Sohn MJ, Lee CH, Choi CY, Han SR, Choi BW. Are there differences in the progression of ossification of the posterior longitudinal ligament following laminoplasty versus fusion?: A metaanalysis. Spine (Phila Pa 1976). 2017;42:887-894.

23. Wang TY, Lubelski D, Abdullah KG, Steinmetz MP, Benzel EC, Mroz TE. Rates of anterior cervical discectomy and fusion after initial posterior cervical foraminotomy. Spine J. 2015;15:971-976.

24. Lubelski D, Healy AT, Silverstein MP, Abdullah K, Thompson NR, Riew KD, et al. Reoperation rates after anterior cervical discectomy and fusion versus posterior cervical foraminotomy: a prospensitymatched analysis. Spine J. 2015;15:1277-1283.

25. Koerner JD, Kepler CK, Albert TJ. Revision surgery for failed cervical spine reconstruction: review article. HSS J. 2015;11:2-8.

26. Shigematsu H, Koizumi M, Matsumori H, Iwata E, Kura T, Okuda A, et al. Revision surgery after cervical laminoplasty: report of five cases and literature review. Spine J. 2015;15:e7-13.

27. Papavero L, Lepori P, Schmeiser G. Revision surgery in cervical spine. Eur Spine J. 2020;29:47-56.

28. Macdonald RL, Fehlings MG, Tator CH, Lozano A, Fleming JR, Gentili F, et al. Multilevel anterior cervical corpectomy and fibular allograft fusion for cervical myelopathy. J Neurosurg. 1997;86:990997. 
29. Yamaura I, Kurosa Y, Matuoka T, Shindo S. Anterior floating method for cervical myelopathy caused by ossification of the posterior longitudinal ligament. Clin Orthop Related Res. 1999;359:27-34.

30. Wang H, Sun J, Tan Y, Li P, Xu X, Wang Y, et al. Anterior controllable antedisplacement and fusion as revision surgery after posterior decompression surgery in patients with ossification of the posterior longitudinal ligament. World Neurosurg. 2019;123:e310-e317.

\section{Tables}

Table 1. Summary of patient demographic and the results of revision ACAF after initial posterior surgery for cervical OPLL 


\begin{tabular}{|ll|}
\hline Variable & Value \\
\hline Sex & \\
\hline Male & 8 \\
\hline Female & 12 \\
\hline Age & $62.1 \pm 8.0$ (52-78) \\
\hline Previous pst op & \\
\hline Laminectomy & 8 \\
\hline Laminoplasty & 9 \\
\hline Decompression & 3 \\
\hline Mean interval btwn initial op and revision, month & $78.0 \pm 48.2(5-180)$ \\
\hline Type of the ossification & \\
\hline Continuous & 10 \\
\hline Segmental & 2 \\
\hline Mixed & 8 \\
\hline k-line & 0 \\
\hline Minus & $179.3 \pm 41.8(120-240)$ \\
\hline Plus & $432.5 \pm 198.3(225-850)$ \\
\hline Mean op time, min & 0 \\
\hline Mean blood loss, ml & 11 \\
\hline Complications, number of patients & 9 \\
\hline CSF leakage & \\
\hline C5 palsy & \\
\hline Postoperative hemotoma & \\
\hline Implants complication & \\
\hline
\end{tabular}

Pst=posterior; op=operation; $b$ twn=between .

Value are expressed as the mean $\pm S D$ (range).

Table 2. Clinical and radiological results of patients. 


\begin{tabular}{|cc|}
\hline Item & Value \\
\hline JOA \\
\hline Before surgery & $8.7 \pm 2.8$ \\
\hline After surgery & $13.4 \pm 2.4 \S$ \\
\hline NDI & \\
\hline Before surgery & $24.4 \pm 3.0$ \\
\hline After surgery & $13.3 \pm 2.7 \S$ \\
\hline VAS arm & \\
\hline Before surgery & $7.3 \pm 1.3$ \\
\hline After surgery & $3.9 \pm 1.4 \S$ \\
\hline VAS neck & \\
\hline Before surgery & $5.9 \pm 2.1$ \\
\hline After surgery & $3.4 \pm 1.4 \S$ \\
\hline SF-36 PCS & \\
\hline Before surgery & $22.3 \pm 3.9$ \\
\hline After surgery & $34.5 \pm 2.1 \S$ \\
\hline SF-36 MCS & $29.6 \pm 4.8$ \\
\hline Before surgery \\
\hline After surgery & $40.4 \pm 2.5 \S$ \\
\hline Cervical lordosis & \\
\hline Before surgery & $3.8 \pm 4.3$ \\
\hline After surgery & $17.0 \pm 4 .{ }^{\S} \S$ \\
\hline
\end{tabular}

JOA: Japanese orthopaedic association scores; VAS: visual analogue score; NDI: neck disability index; SF-36:Short-Form 36.

Value are expressed as the mean $\pm \mathrm{SD}$ (range)

$\S \mathrm{P}<0.05$, compared with the data before surgery. 
Figures
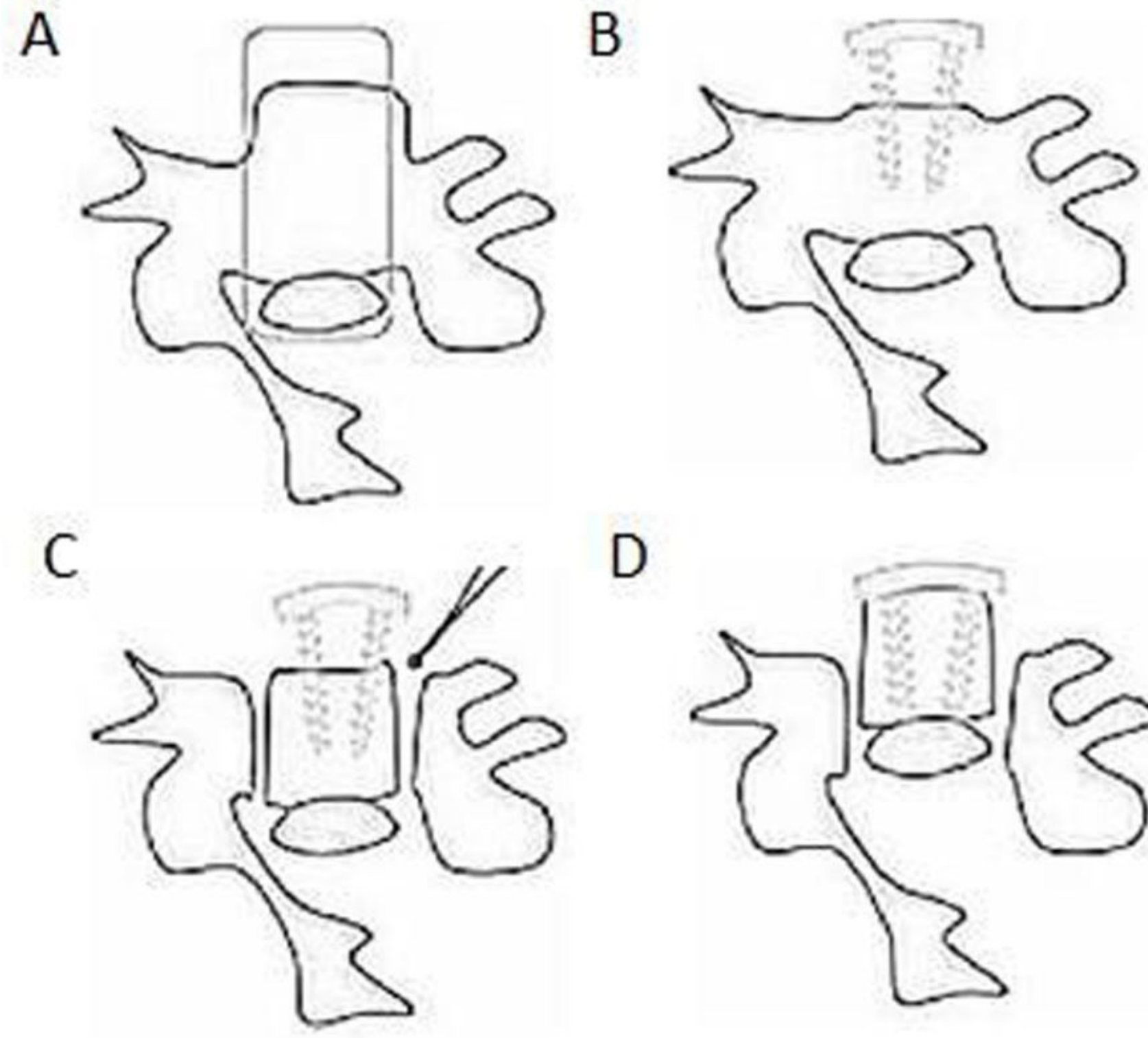

D

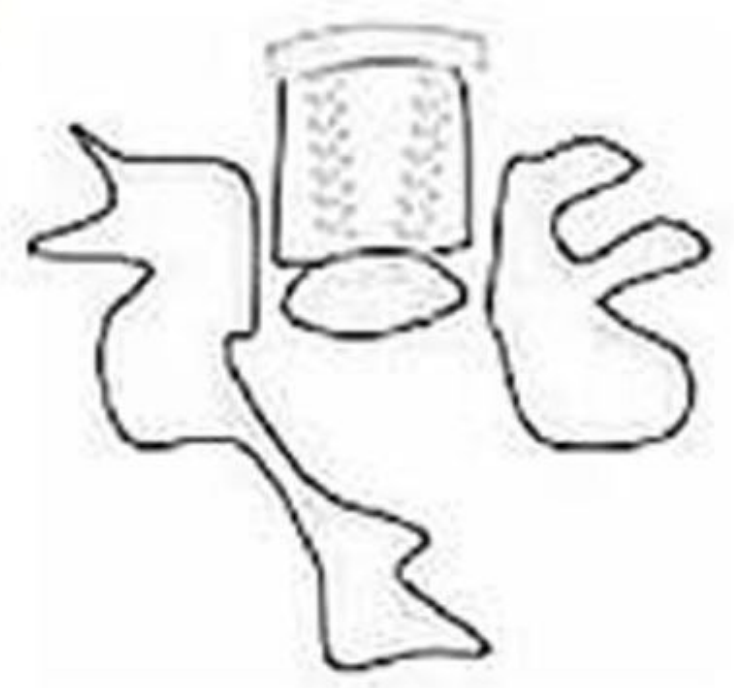

Figure 1

Illustration of the procedures of the ACAF technique. A: The bilateral border of the OPLL mass (dash lines); B: Installation of the anterior cervical plate (installation of the "bridge"); C: Bilateral osteotomies of the VOC; D: Controllable antedisplacement of the VOC by the screws. 


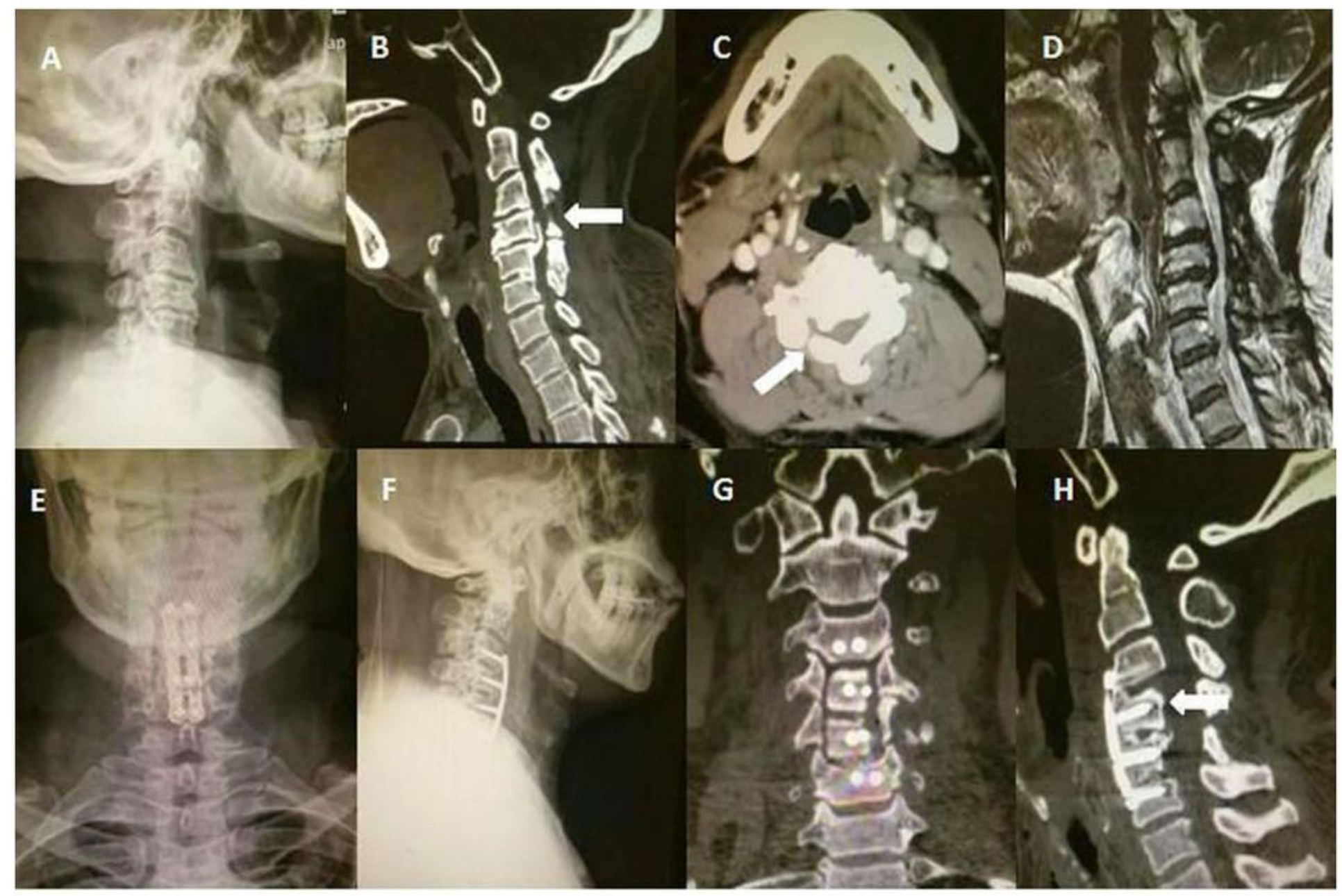

Figure 2

A case of 59 years old man who needed a revision surgery 5 years after initial posterior decompressing surgery. A: The lateral image showed that the cervical kyphosis occurred after the initial posterior surgery; B-C: The CT scan showed that there was only a window decompressing without fixation in the initial posterior surgery (arrows); D: the MRI showed that the cervical spinal cord of C4-5 was compressed by the OPLL; E-F: the postoperative anterior-posterior and lateral image showed the good device position and still the bad cervical lordosis; G-H: The postoperative CT scan show that the bilateral troughs are created among the widest edge of the OPLL, and we hoisted the VOC by the screws (arrows). We usually used a 2-mm high-speed cutting burr and a $1 \mathrm{~mm}$ Kerrison rongeurs to remove the posterior vertebral wall on the bottom of the troughs. 


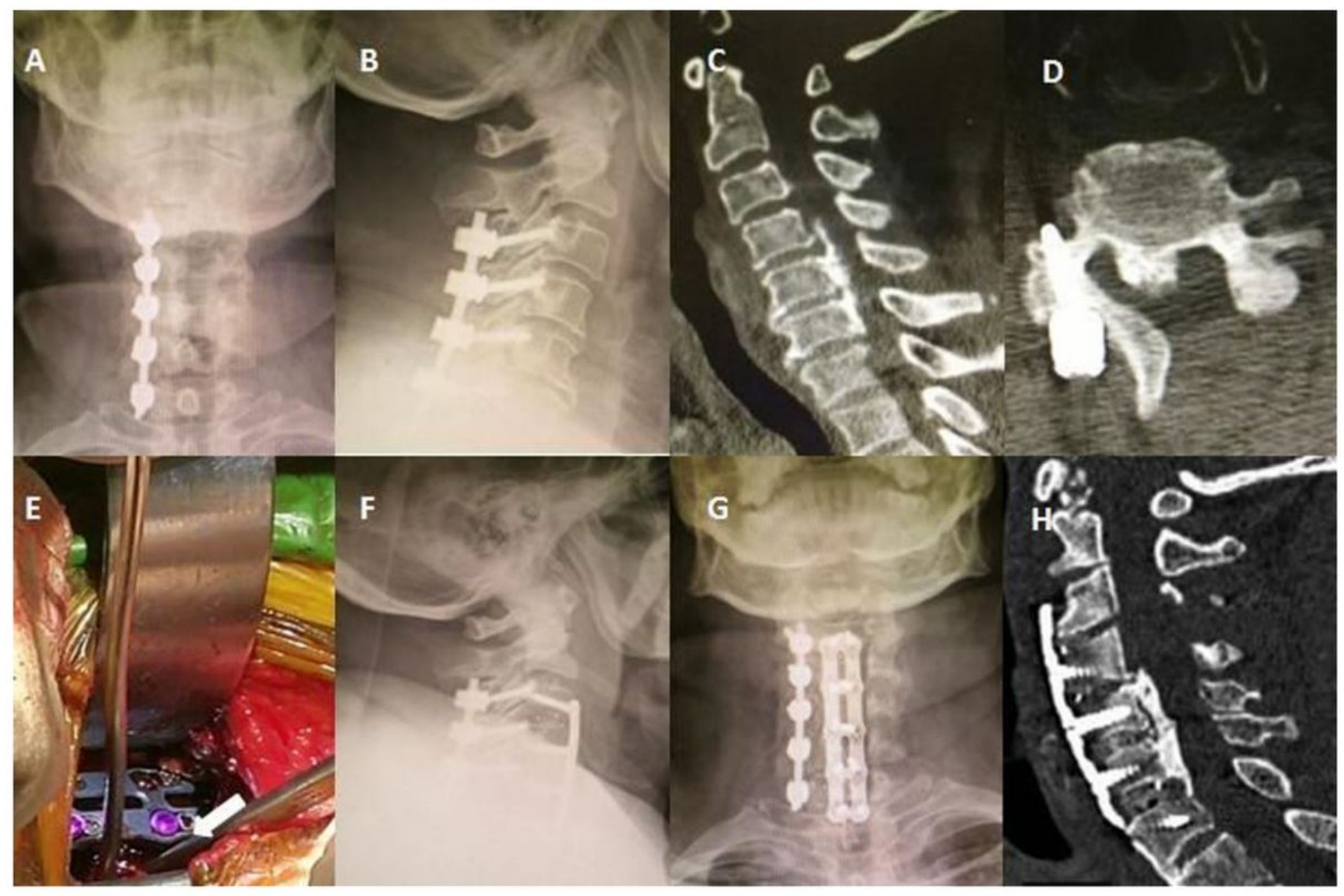

Figure 3

A case of 61 years old man who needed a revision surgery 12 months after initial posterior laminectomy. A-B: The anterior-posterior and lateral image showed the loss of cervical lordosis after the initial laminectomy; C-D: The CT scan showed that there was a continuous type of OPLL, and only a semilaminectomy with one-side lateral mass fixation was done in the initial surgery; $\mathrm{E}$ : The intraoperative photo showed that after installation of the intervertebral cages and anterior cervical plate, we used a 1 $\mathrm{mm}$ Kerrison rongeurs to remove the posterior vertebral wall on the bottom of the troughs for isolation of the VOC (arrows); F-G: The postoperative anterior-posterior and lateral image showed the good internal fixation position and the improved cervical lordosis; $\mathrm{H}$ : The $\mathrm{CT}$ scan show that the VOC was hoisted forward, and the cervical spinal canal was obviously wider than before. 
A

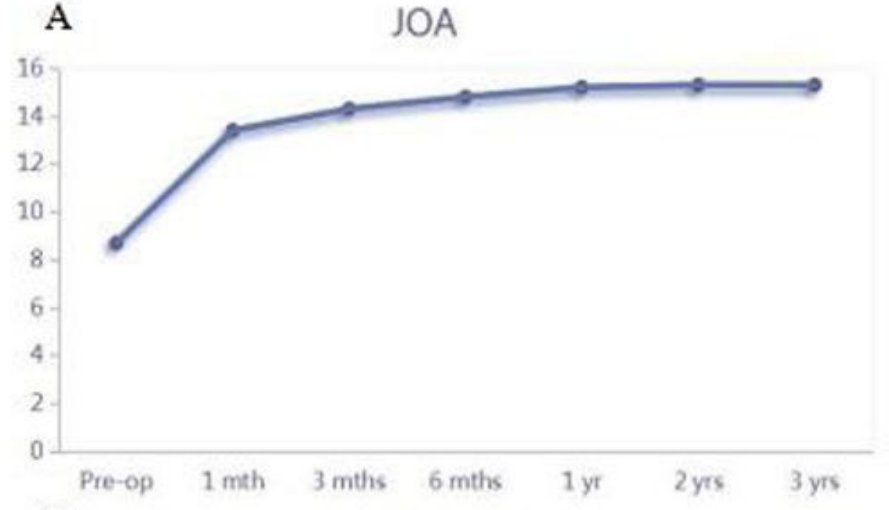

$\mathrm{C}$
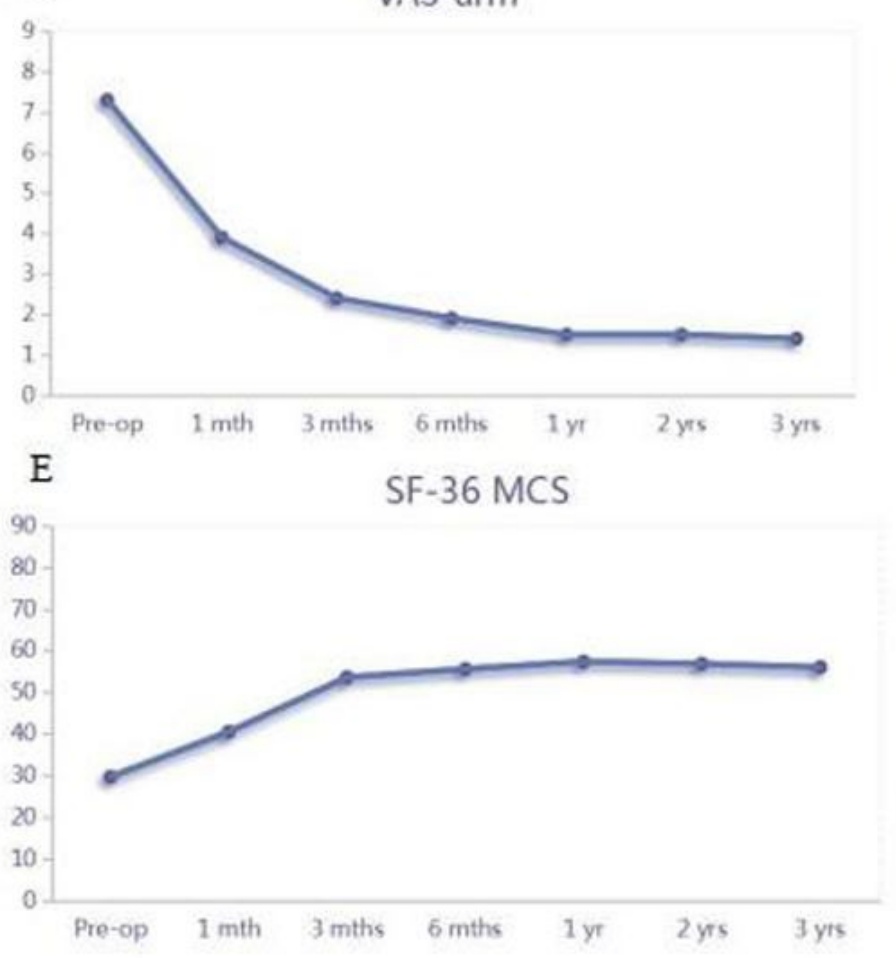

B
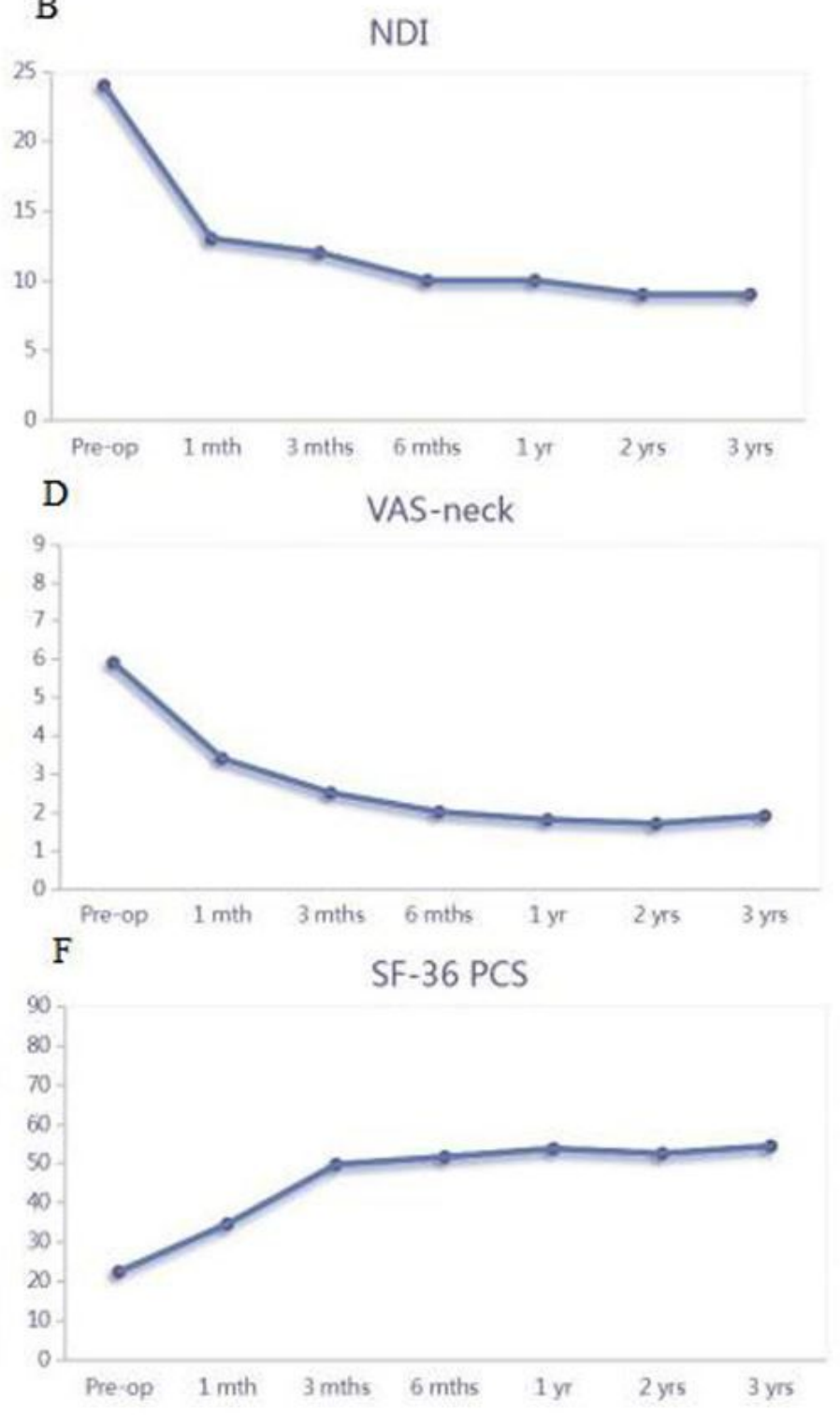

\section{Figure 4}

Graphs showing changes in clinical outcomes over time (mean value). (A) Japanese Orthopedic Association score. (B) Neck Disability Index. (C) Visual analog scale (VAS) arm. (D) VAS neck. (E) Shortform 36-item (SF-36) mental subscores. (F) SF-36 physical subscores. 